\title{
Development and Validation of a Chromatographic and Electrophoretic Method for the Determination of Amikacin and Urea in Bronchial Epithelial Lining Fluid
}

\author{
Mohamed Nouri El-Attug • Shruti Chopra $\cdot$ \\ Rajya Lakshmi Dhulipalla • Karel Allegaert • \\ Anne Smits · Ann Van Schepdael · Erwin Adams
}

Received: 29 February 2012/Revised: 16 April 2012/ Accepted: 23 April 2012

(C) Springer-Verlag 2012

\begin{abstract}
Methods were developed to determine amikacin and urea in bronchial epithelial lining fluid of neonates. Urea was determined as ammonium by capillary electrophoresis in combination with capacitively coupled contactless conductivity detection $\left(\mathrm{CE}-\mathrm{C}^{4} \mathrm{D}\right)$. The ammonium was produced by enzymatic conversion of urea with urease enzyme. The background electrolyte (BGE) contained $30 \mathrm{mM}$ malic acid, adjusted to $\mathrm{pH} 4.1$ by L-arginine, and $10 \mathrm{mM}$ 18-Crown-6. Lithium was used as internal standard. A $+30 \mathrm{kV}$ was applied on a fused silica capillary with $75 \mu \mathrm{m}$ internal diameter (ID) and total length of $65 \mathrm{~cm}$ (41 $\mathrm{cm}$ to $\mathrm{C}^{4} \mathrm{D}$ detector). The optimized separation was obtained in $<3$ min with good linearity $\left(R^{2}=0.9998\right)$ for urea concentrations ranging from 0.6 to $24 \mathrm{mg} \mathrm{L}^{-1}$. It also shows a good repeatability expressed by the RSD which is 0.7 and $1.3 \%$ for intraday and interday precision, respectively. The LOD and LOQ are 0.14 and $0.5 \mathrm{mg} \mathrm{L}^{-1}$ respectively. As the $C E-C^{4} D$ method was not sensitive enough for amikacin, the latter was determined using liquid chromatography combined with pulsed electrochemical detection (LC-PED). The LOQ for amikacin base
\end{abstract}

\section{N. El-Attug · S. Chopra · R. L. Dhulipalla}

A. Van Schepdael · E. Adams $(\square)$

Laboratory for Pharmaceutical Analysis,

Faculteit Farmaceutische Wetenschappen, KU Leuven,

$\mathrm{O}$ and N 2, PB 923, Herestraat 49, 3000 Leuven, Belgium

e-mail: erwin.adams@pharm.kuleuven.be

M. N. El-Attug ( $\varangle)$

Department of Pharmaceutical Chemistry, Faculty of Pharmacy,

Tripoli University, Tripoli, Libya

e-mail: md.elattug@pharm.kuleuven.be

K. Allegaert · A. Smits

Neonatal Intensive Care Unit, University Hospitals Leuven, Leuven, Belgium was found to be $0.06 \mathrm{mg} \mathrm{L}^{-1}$. In addition, the linearity was good $\left(R^{2}>0.995\right)$ as well as the repeatability $(\mathrm{RSD}=0.1 \%, n=3)$. For both the CE and LC method, no interference of matrix components was observed and the recoveries were found to be close to $100 \%$.

Keywords CE-C ${ }^{4}$ D $~ L C-P E D \cdot$ Urea $\cdot$ Amikacin Bronchial fluid

\section{Introduction}

Amikacin is a semi-synthetic aminoglycoside antibiotic, a family of polycationic pseudo-oligosaccharide compounds, consisting of aminosugars joined by a glycosidic linkage to an aminocyclitol nucleus (2-deoxy-streptamine) in a central position. Amikacin is obtained by the acylation of kanamycin A with L-(-)- $\gamma$-amino- $\alpha$-hydroxybutyric acid (L-HABA) at the C-1 amino group of the 2-deoxystreptamine moiety [1] as shown in (Fig. 1).

Amikacin is often used in neonates for the treatment of Gram-negative infections which are resistant to other aminoglycosides (such as kanamycin, gentamicin and tobramycin) because amikacin has fewer target sites for enzymatic attack [2]. The bactericidal efficacy of amikacin is related to its peak serum concentration and the possibility to reach therapeutic levels at the infection site. In this study, antibiotic levels in the lung of newborns are of specific interest. As measuring amikacin concentrations in the lung is not easy, it is usually represented by concentration in the epithelial lining fluid (ELF) through bronchoalveolar lavage (BAL). To correct for the dilution of the latter, the amikacin concentration in ELF was calculated from the concentration in BAL using the concentration of urea. Urea is a small endogenous marker and its 


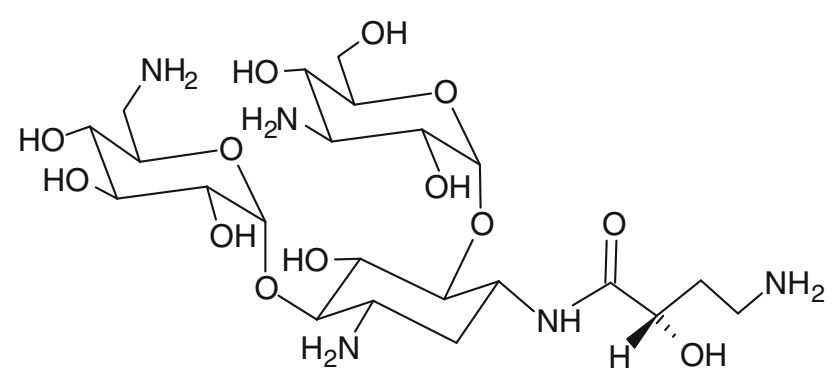

Fig. 1 Chemical structure of amikacin

concentration is considered the same in ELF as in serum. Significant diffusion of urea across the epithelium during the BAL procedure does not occur.

Therefore, both amikacin and urea should be determined in the BAL fluid. The separation and detection of amikacin and urea have been a great challenge, due to the lack of UV absorbing properties. Various methods have been applied for determination of aminoglycosides in various matrices, including microbiological assay [3], radioenzymatic assay [4], immunoassays [5], liquid chromatography (LC) [6-9] and capillary electrophoresis (CE) [10-18]. Several of these methods used precolumn or postcolumn derivatization with either UV or fluorescence detection [6, 14, 15]. Although these detection methods are quite sensitive, the derivatization step is time consuming and needs wellcontrolled experimental conditions to obtain repeatable results. These derivatization methods have proved to be tedious and time consuming. They also may lead to incomplete reactions or to formation of by-products which will lead to difficulties in quantitation. For the sake of simplicity and correct quantitation, direct detection methods are preferred. Among these, in combination with LC, pulsed electrochemical detection (PED) is advisable [7-9]. Combined with CE, borate complexation [17], indirect UV detection [12], amperometric detection [18] and UV detection, performed in Tris buffer at $\mathrm{pH} 9.1$ with high concentration of sodium pentanesulfonate (SPS) [10] or in pyrophosphate buffer [11] have been described for the analysis of aminoglycosides. However, these CE methods are neither very sensitive nor selective.

Numerous methods have been applied for the determination of urea in various matrices, such as urine and serum [19], but to our best knowledge there is no method to determine urea in epithelial lining fluid. Urea is routinely determined in blood serum samples because it serves as a predictive index of renal failure and as a diagnostic aid in distinguishing between the various causes of renal insufficiency. Urea was one of the first substances to be determined in biological fluids [20]. Early methods for measuring urea involved chemical reagents, of which only $o$-phthalaldehyde [21] and diacetylmonoxime [22] are still used. Because of the use of corrosive reagents and incubation, these assays have been widely replaced by enzymatic methods, which include hydrolysis of urea by urease. The urea concentration can then be measured directly by a differential $\mathrm{pH}$ technique [23]. The other enzymatic methods require a second step: the photometric measure of ammonium generated in the urease step. The Berthelot reaction [24] is the only one still being used, but also here the reagents are corrosive and the method cannot easily be automated.

The most common way to detect urea is to employ the enzyme urease to catalyze the hydrolysis of urea and to determine the products formed:

$\mathrm{NH}_{2} \mathrm{CONH}_{2}+2 \mathrm{H}_{2} \mathrm{O}+\mathrm{H}^{+} \stackrel{\text { urease }}{\longrightarrow} 2 \mathrm{NH}_{4}^{+}+\mathrm{HCO}_{3}^{-}$

Because ammonium and bicarbonate are not optically active, in clinical analysis this reaction is usually followed by a second enzymatically catalyzed step in which the conversion of the cofactor NADH is used for indirect quantification via molecular absorption photometry in the UV range [25]:

$2 \mathrm{NH}_{4}^{+}+\alpha$-ketoglutarate $+2 \mathrm{NADH} \stackrel{\text { dehydrogenase }}{\longrightarrow} 2 \mathrm{~L}$-glutamate $+2 \mathrm{NAD}^{+}+2 \mathrm{H}_{2} \mathrm{O}$

For studies of the enzyme kinetics of urease, this twostep procedure is not suitable and therefore alternative methods, using for example chemiluminescence [26], or ammonium-selective electrodes [27] have been developed for this purpose. Duffy et al. [28] described the batch wise use of a specially designed cell for measurement of the increase in bulk conductance due to the charged products obtained in the enzymatic conversion of urea. Thavarungkul et al. [29] used a flow-through system in which the urea was separated from the sample matrix by dialysis and then converted to the charged products in a reactor with immobilized urease. Quantification was carried out by conductivity measurement. The use of CE- $C^{4} \mathrm{D}$ for the monitoring of enzymatic reactions has been demonstrated for conversions of ethanol, glucose, ethyl acetate and ethyl butyrate [30]. Enzymatic conversion of urea to ammonium by conventional or microchip CE-C ${ }^{4} \mathrm{D}$ has also been described [31]. Although not yet described, $\mathrm{C}^{4} \mathrm{D}$ should also be able to detect amikacin.

Sensitive detection of the low concentration of amikacin and urea in bronchial fluid has not been described yet. Therefore, this work will investigate the usefulness of CE$\mathrm{C}^{4} \mathrm{D}$, a relatively new and interesting combination to analyse polar compounds with no (strong) UV absorbing chromophore like amikacin and urea. If the sensitivity is insufficient to determine amikacin, LC-PED can be tried as an alternative. 


\section{Materials and Methods}

\section{Reagents and Samples}

All chemicals used were of analytical grade. Malic acid was purchased from Janssen Chimica (Beerse, Belgium), L-arginine base and sodium acetate from Applichem $\mathrm{GmbH}$ (Darmstadt, Germany), magnesium hydroxide, calcium hydroxide, anhydrous sodium sulphate and tetrahydrofuran from Merck (Darmstadt, Germany), lithium hydroxide, phosphoric acid $85 \%$, potassium dihydrogen phosphate and sodium-1-octanesulphonate from Acros Organics (Geel, Belgium), sodium hydroxide from Riedel-deHaën (Seelze, Germany), sodium chloride from Fisher chemicals (Leicestershire, UK), ammonium formate from Fluka AG (Buchs, Switzerland), urea from Federa S.V. (Brussels, Belgium), urease (Type IX from jack beans 50,000-100,000 units/g solid) and 18-Crown-6 were from Sigma-Aldrich Chemie GmbH (Steinheim, Germany).

A $0.2 \mathrm{M}$ phosphate buffer for the mobile phase was prepared by mixing a $0.2 \mathrm{M}$ solution of phosphoric acid and a $0.2 \mathrm{M}$ solution of potassium dihydrogen phosphate until $\mathrm{pH} 3.0$ was achieved. The $0.5 \mathrm{M}$ sodium hydroxide solution for post-column addition was prepared using $50 \%$ sodium hydroxide $(\mathrm{m} / \mathrm{m})$ aqueous solution (J.T. Baker, Deventer, The Netherlands). All solutions were prepared using ultrapure MilliQ-water (Millipore, Milford, MA, USA) and were filtered through a $0.2-\mu \mathrm{m}$ membrane filter (Dassel, Germany). The pH value of the buffers was measured and adjusted with the aid of a $\mathrm{pH}$ meter Metrohm 691 (Herisau, Switzerland). Malic acid buffers with $\mathrm{pH}$ values equal to or higher than 3.0 were prepared with malic acid and the $\mathrm{pH}$ was adjusted with $100 \mathrm{mM}$ solutions of L-arginine.

During method development, sample stock solutions of urea prepared at a concentration of $1 \mathrm{~g} \mathrm{~L}^{-1}$ in water and stored at $7{ }^{\circ} \mathrm{C}$ were used for at most 1 week.

\section{CE Instrumentation and Conditions}

The CE experiments were performed on a P/ACE MDQ instrument (Beckman Coulter, Inc. Fullerton, CA, USA), coupled to an eDAQ $\mathrm{C}^{4} \mathrm{D}$ system (eDAQ, Denistone East, Australia). Uncoated fused silica capillaries were purchased from Polymicro Technologies (Phoenix, AZ, USA). New capillaries were conditioned at $45^{\circ} \mathrm{C}$ by rinsing with $1 \mathrm{M} \mathrm{NaOH}$ (10 min), $0.1 \mathrm{M} \mathrm{NaOH}$ (30 min), wait for $30 \mathrm{~min}$ and water $(10 \mathrm{~min})$. Daily at the beginning, the capillary was rinsed at $45{ }^{\circ} \mathrm{C}$ with $1 \mathrm{M} \mathrm{NaOH}(5 \mathrm{~min})$, $0.1 \mathrm{M} \mathrm{NaOH}(5 \mathrm{~min})$, water $(5 \mathrm{~min})$ and BGE at $25{ }^{\circ} \mathrm{C}$ for (5 min); all the steps were performed at $137.9 \mathrm{kPa}$ pressure. The inlet/outlet vials were replaced every three runs. The eDAQ $\mathrm{C}^{4} \mathrm{D}$ detector was employed at a peak-to-peak amplitude of $100 \mathrm{~V}$ and the frequency was $1,200 \mathrm{kHz}$. The data were processed using licensed PowerChrom v2 software (eDAQ). Further data presentation was done by both PowerChrom v2 and $32 \mathrm{Karat}^{\mathrm{TM}} 4.0$ softwares.

The optimized method is performed using a background electrolyte (BGE) composed of $30 \mathrm{mM}$ malic acid, $10 \mathrm{mM}$ 18 Crown-6, adjusted to $\mathrm{pH} 4.1$ by $\mathrm{L}$-arginine. Lithium was used as an internal standard. $30 \mathrm{kV}$ normal polarity was applied on a fused silica capillary with $75 \mu \mathrm{m}$ ID, $375 \mu \mathrm{m}$ OD and total length of $65 \mathrm{~cm}$ ( $41 \mathrm{~cm}$ to $C^{4} D$ detector). The capillary was rinsed between runs for 1 min with $0.1 \mathrm{M}$ $\mathrm{NaOH}, 1$ min with water and 3 min with buffer at $137.9 \mathrm{kPa}$. Samples were hydrodynamically introduced at a pressure of $5.5 \mathrm{kPa}$ for $4 \mathrm{~s}$ and separated at $25^{\circ} \mathrm{C}$.

\section{LC Instrumentation and Conditions}

The mobile phase was delivered by a LC pump (L-6200 Intelligent pump, Merck-Hitachi, Darmstadt, Germany) and samples were injected using an automatic autosampler (Elite LaChrom L-2200, Merck-Hitachi). The column was immersed in a water bath and maintained at $40{ }^{\circ} \mathrm{C}$ with a heating immersion circulator (Julabo EC, Seelbach, Germany). $0.5 \mathrm{M}$ sodium hydroxide was added post-column using a helium pressurized reservoir to increase the $\mathrm{pH}$ of the column effluent above 12 . This alkaline $\mathrm{pH}$ is necessary to enhance the detection sensitivity. The addition of the post-column solution should be pulse-free to avoid disturbances in the baseline. After mixing the $\mathrm{NaOH}$ solution and mobile phase in a mixing coil $(1.2 \mathrm{~m}, 500 \mu \mathrm{L}$ ) (Dionex, Sunnyvale, CA, USA), the resulting solution entered into the electrochemical cell of the PED (Antec Decade II, Leyden, The Netherlands). This measuring cell was put in a hot-air oven to keep the temperature constant at $35{ }^{\circ} \mathrm{C}$. An overview of the chromatographic conditions is given in Table 1. Data acquisition software (Chromeleon, Dionex) was used to record the signal.

\section{Sample Preparation for CE- $\mathrm{C}^{4} \mathrm{D}$}

A stock reference solution of urea was prepared at $1 \mathrm{~g} \mathrm{~L}^{-1}$ in MilliQ water. Reference solutions in water were prepared at concentrations of $0.6,1.2,3.0,6.0,12,24 \mathrm{mg} \mathrm{L}^{-1}$ (expressed as urea).

Samples were collected from newborns treated with amikacin, using endotracheal suctioning as described in literature $[9,32]$. They were kept in the freezer till analysis was performed. Blank samples from neonates were also available. BAL was centrifuged for $2 \mathrm{~min}$ at a speed of $13,147 \mathrm{~g}$ using a mini-Spin plus (Eppendorf, Hamburg, Germany). A volume of $100 \mu \mathrm{L}$ of supernatant of BAL was pipetted into a $1.5 \mathrm{~mL}$ Eppendorf vial. A $100 \mu \mathrm{L}$ of $\left(0.1 \mathrm{~g} \mathrm{~L}^{-1}\right)$ lithium as an internal standard and $100 \mu \mathrm{L}$ of 
Table 1 An overview of the chromatographic conditions

\begin{tabular}{|c|c|c|}
\hline Stationary phase & \multicolumn{2}{|c|}{$100 \times 2.1 \mathrm{~mm} 3 \mu \mathrm{m}$ Hypersil BDS C18 } \\
\hline Guard column & \multicolumn{2}{|c|}{ Gemini $\mathrm{C} 184 \times 2 \mathrm{~mm}$} \\
\hline \multirow{5}{*}{$\begin{array}{l}\text { Mobile phase composition } \\
\text { per liter }\end{array}$} & \multicolumn{2}{|c|}{ Sodium-1-octanesulphonate $1.5 \mathrm{~g}$} \\
\hline & \multicolumn{2}{|c|}{ Anhydrous sodium sulphate $20 \mathrm{~g}$} \\
\hline & \multicolumn{2}{|c|}{ Tetrahydrofuran $15 \mathrm{~mL}$} \\
\hline & \multicolumn{2}{|c|}{$0.2 \mathrm{M}$ phosphate buffer $\mathrm{pH} 3250 \mathrm{~mL}$} \\
\hline & \multicolumn{2}{|c|}{ Milli-Q Water up to $1,000 \mathrm{~mL}$} \\
\hline Flow rate of mobile phase & \multicolumn{2}{|c|}{$0.3 \mathrm{~mL} / \mathrm{min}$} \\
\hline Injection volume & \multicolumn{2}{|l|}{$99 \mu \mathrm{L}$} \\
\hline Column temperature & \multicolumn{2}{|l|}{$40{ }^{\circ} \mathrm{C}$} \\
\hline $\begin{array}{l}\text { Post column addition of } \\
0.5 \mathrm{M} \mathrm{NaOH}\end{array}$ & \multicolumn{2}{|l|}{$0.13 \mathrm{~mL} / \mathrm{min}$} \\
\hline \multicolumn{3}{|l|}{$\begin{array}{l}\text { Pulsed electrochemical } \\
\text { detector }\end{array}$} \\
\hline Working electrode & \multicolumn{2}{|l|}{ Gold } \\
\hline Reference electrode & \multicolumn{2}{|c|}{ HyREF } \\
\hline Counter electrode & \multicolumn{2}{|c|}{$\begin{array}{l}\text { Carbon filled with } \\
\text { polytetrafluoroethylene (PTFE) }\end{array}$} \\
\hline \multirow[t]{4}{*}{ Detector settings } & $t(\mathrm{~s})$ & $E$ (volt) \\
\hline & $0.0-0.40$ & +0.05 \\
\hline & $0.41-0.60$ & +0.70 \\
\hline & $0.61-1.00$ & -0.15 \\
\hline Integration period & \multicolumn{2}{|l|}{$0.20-0.40 \mathrm{~s}$} \\
\hline Sensitivity & \multicolumn{2}{|l|}{$5 \mu \mathrm{A}$} \\
\hline
\end{tabular}

( $\left.0.2 \mathrm{~g} \mathrm{~L}^{-1}\right)$ urease were added and completed to $1,000 \mu \mathrm{L}$ with water, incubated and centrifuged. $100 \mu \mathrm{L}$ of the supernatant was transferred into a micro-sample vial and directly injected to CE-C $\mathrm{C}^{4} \mathrm{D}$.

\section{Sample Preparation for LC-PED}

A stock reference solution was prepared at $0.5 \mathrm{~g} \mathrm{~L}^{-1}$ by dissolving $25 \mathrm{mg}$ of amikacin base in $50 \mathrm{~mL}$ of mobile phase. Reference solutions in mobile phase were prepared at concentrations of $0.06,0.08,0.1,0.2,0.5,1,2,3$ and $4 \mathrm{mg} \mathrm{L}^{-1}$ (expressed as amikacin base). BAL was centrifuged for $3 \mathrm{~min}$ at $6,708 \mathrm{~g}$. The supernatant was taken and directly injected to LC.

\section{Results and Discussion}

\section{Method Development of CE-C ${ }^{4} \mathrm{D}$}

\section{Optimization of $C E-C^{4} D$}

The buffer $\mathrm{pH}$, as well as the ionic strength influences the electrophoretic mobility of the analytes through the capillary. Hence, the choice of the BGE constituents is crucial for separation, conductivity and mobility differences of the analytes. Starting with the buffer constituents, malic acid and L-arginine, urea could not determined as it had the same mobility as sodium ions, which are always present in biological fluids. Urea has a pKa value of 0.18 , making it slightly protonated at the acid conditions used here. In view of its co-migration with sodium, the enzymatic reaction with urease was used to convert urea to ammonium. 18-Crown- 6 was added to the BGE to enable separation of ammonium from potassium ions by partial complexation. Potassium ions are always present in biological fluids and have the same charge and similar size as ammonium.

A series of experiments were carried out in order to find the optimal combination of malic acid, L-arginine and 18-Crown-6 for determining urea and amikacin. A BGE containing $30 \mathrm{mM}$ malic acid, adjusted to $\mathrm{pH} 4.1$ with L-arginine and $10 \mathrm{mM} 18$-Crown- 6 was chosen because it gave the highest signal-to-noise ratio and best overall resolution. Magnesium hydroxide, calcium hydroxide and lithium hydroxide were tried as internal standard to correct imprecision in volume injection, common in CE. Lithium hydroxide was chosen because the two other might give false results due to the natural occurrence of magnesium and calcium in the biological fluid. Only for patients taking lithium as antidepressant medication, there can be a problem, but this is irrelevant for the neonates studied here.

At the $\mathrm{pH}$ of the BGE, ammonia from urea will be present as ammonium and amikacin will be positively charged. Under the optimized conditions with normal polarity, the migration order was observed to be: ammonium, potassium and urease, sodium (or matrix peak), lithium, magnesium, calcium and amikacin (Fig. 2c). The separation was obtained in $<3 \mathrm{~min}$. Separation of the cations (ammonium, potassium and urease, sodium, lithium, magnesium, calcium and amikacin) is achieved based on their electrophoretic mobilities by their weights, number of positive charges and complexation with 18-Crown-6.

The separation voltage was increased to $30 \mathrm{kV}$, the maximum of the equipment, which was still in the linear range of Ohm's law.

\section{Optimization of Enzymatic Reaction}

The method described by Schuchert-Shi et al. [31] was used as starting point for further method development. Solutions of urea $\left(0.1 \mathrm{~g} \mathrm{~L}^{-1}\right)$ and urease $\left(0.2 \mathrm{~g} \mathrm{~L}^{-1}\right)$ were prepared and dissolved in MilliQ water. Different combinations of urease concentrations, different incubation time intervals of $0,20,40,60,120 \mathrm{~min}$ and $24 \mathrm{~h}$ at room temperature and $37{ }^{\circ} \mathrm{C}$ were attempted to obtain maximum enzymatic reaction and thus ammonium production. Mixing was performed using a Thermomixer comfort (Eppendorf, Hamburg, Germany). Next, the solution was centrifuged at room temperature at a speed of $13,147 \mathrm{~g}$. 


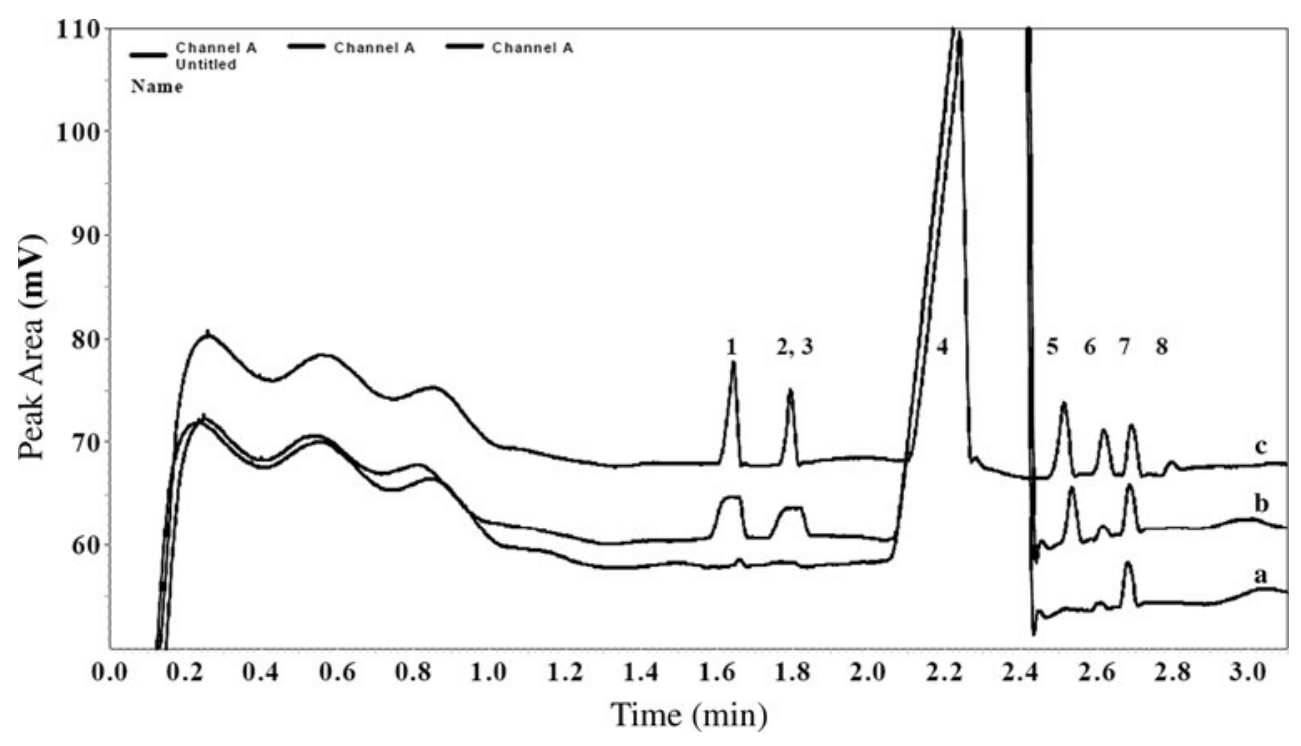

Fig. 2 Typical CE-C ${ }^{4} \mathrm{D}$ electropherograms: a Blank bronchial fluid not treated with urease, $\mathbf{b}$ bronchial fluid sample containing urea treated with urease, $\mathbf{c}$ reference sample containing $2 \mathrm{mg} \mathrm{L}^{-1}$ urea, $5 \mathrm{mg} \mathrm{L}^{-1}$ amikacin, $20 \mathrm{mg} \mathrm{L}^{-1}$ urease, $10 \mathrm{mg} \mathrm{L}^{-1}$ magnesium, calcium, and lithium (internal standard) each in Milli Q water. 1 ammonium, 2 potassium, 3 urease, 4 sodium (matrix peak), 5 internal standard,

$100 \mu \mathrm{L}$ of the supernatant was transferred into a microsample vial and directly injected to CE. At $20 \mathrm{~min}$ and $37^{\circ} \mathrm{C}$, the maximum production of ammonium in water was reached and so these conditions were selected for determination of urea in BAL.

\section{Validation of CE-C ${ }^{4} \mathrm{D}$}

\section{Urea}

For calculation, relative corrected peak areas were used. Limit of detection (LOD) and limit of quantification (LOQ) values are calculated as 3 and 10 times the signal-to-noise ratio $(\mathrm{S} / \mathrm{N})$. Good sensitivity was observed, with $\mathrm{LOD}$ and LOQ values of 0.14 and $0.5 \mathrm{mg} \mathrm{L}^{-1}$, respectively. A good linear relationship $\left(R^{2}=0.9998\right)$ was obtained for urea with 6 concentration points injected in triplicate for concentrations ranging from 0.6 to $24 \mathrm{mg} \mathrm{L}^{-1}$. Lithium hydroxide was used as internal standard. The following regression equation was obtained: $y=0.5382 x+0.146$, $S_{y, x}=0.07$, where $y:$ relative area, $x$ : concentration $\left(\mathrm{mg} \mathrm{L}^{-1}\right), S_{y, x}$ : standard error of estimate. The repeatability of the optimized method was expressed as the relative standard deviation (\%RSD) of the relative corrected peak areas. Intraday precision was $0.7 \%(n=6)$ and interday precision for 3 days was $1.3 \%$ ( $n=18,6 \times 3$ days). This method provided conditions without interference of matrix components (see Fig. 2) and the recovery was found to be 97.9 and $99.3 \%$ for BAL spiked with urea at concentrations of 1.8 and $7.2 \mathrm{mg} \mathrm{L}^{-1}$, respectively.
6 magnesium, 7 calcium, 8 amikacin. CE capillary: uncoated fused silica $75 \mu \mathrm{m}$ ID, $375 \mu \mathrm{m}$ OD (65 cm total length, effective $41 \mathrm{~cm}$ to $\mathrm{C}^{4} \mathrm{D}$ detector); voltage, $30 \mathrm{kV}$ in normal polarity; temperature, $25{ }^{\circ} \mathrm{C}$; injection: inlet pressure $5.5 \mathrm{kPa}$ for $4 \mathrm{~s}$; BGE: $30 \mathrm{mM}$ malic acid, adjusted to $\mathrm{pH} 4.1$ by L-arginine and $10 \mathrm{mM} 18$-Crown- 6

\section{Amikacin}

The LOD and LOQ for amikacin base in water were found to be 0.92 and $3.1 \mathrm{mg} \mathrm{L}^{-1}$, respectively. This means that the $\mathrm{CE}-\mathrm{C}^{4} \mathrm{D}$ method is not sensitive enough to quantify amikacin at its excepted concentration in BAL. Based on the good results obtained for the determination of amikacin in cerebrospinal fluid [9], the performance of LC-PED was then evaluated.

\section{Validation of LC-PED}

\section{Amikacin}

Quantification of amikacin was based on the method described by Brajanoski et al. [9]. No interference of blank compounds was noticed (Fig. 3). The LOD and LOQ for amikacin base were found to be 0.018 and $0.06 \mathrm{mg} \mathrm{L}^{-1}$, respectively. This is about 50 times more sensitive than for the CE-C ${ }^{4} \mathrm{D}$ method and allows to determine the expected concentration in BAL. Good linearity $\left(R^{2}=0.9988\right)$ was obtained for amikacin. A linear relationship was obtained with six concentration points injected in triplicate for the range from 0.06 to $4.0 \mathrm{mg} \mathrm{L}^{-1}$. The following regression equation was obtained: $y=2,477.1 x+142.4, S_{y, x}=156$, where $y$ : area, $x$ : concentration $\left(\mathrm{mg} \mathrm{L}^{-1}\right), S_{y, x}$ standard error of estimate. The repeatability was checked by analyzing a $1.0 \mathrm{mg} \mathrm{L}^{-1}$ amikacin base solution three times. The RSD on the peak area was $0.1 \%$. The recovery was found to be 99.1 and $100.9 \%$ for BAL spiked with 


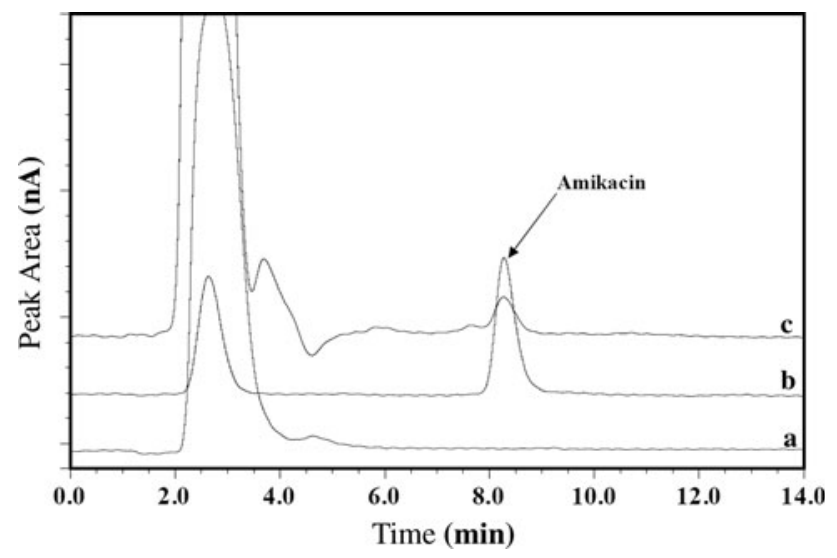

Fig. 3 Typical LC-PED chromatograms: a blank bronchial fluid, b $1 \mathrm{mg} \mathrm{L}^{-1}$ amikacin-based reference solution, $\mathbf{c}$ real bronchial fluid sample containing amikacin

amikacin base at concentrations of 0.2 and $2.0 \mathrm{mg} \mathrm{L}^{-1}$, respectively.

\section{Urea}

As urea lacks hydroxyl groups, which is important in this mode of detection, it could not be detected by PED. As a consequence, it was quantified using the CE- $\mathrm{C}^{4} \mathrm{D}$ method.

Application of the Optimized Methods

for Determination of Urea and Amikacin in BAL

The optimized CE-C ${ }^{4} \mathrm{D}$ method was applied for determination of urea and LC-PED for determination of amikacin in several BAL samples. Typical electropherograms and chromatograms are shown in (Fig. 2a, b) and (Fig. 3), respectively. The urea concentration was found to vary from 4.7 to $46.1 \mathrm{mg} \mathrm{L}^{-1}$ and the amikacin concentration from 0.08 to $0.96 \mathrm{mg} \mathrm{L}^{-1}$. The clinical and pharmacokinetic interpretation of the amikacin disposition is discussed in the Ref. [33] which does however not contain the analytical method development and validation.

\section{Conclusion}

The goal of this work was the development, optimization and validation of a selective method for the determination of amikacin and urea in BAL.

A CE method with $\mathrm{C}^{4} \mathrm{D}$ detection was developed and validated for the determination of urea as ammonium. Although the method can also detect amikacin, its sensitivity was insufficient to determine the low concentration in BAL. Therefore, a more sensitive LC-PED method was used. Both methods proved to be linear and free of matrix interference.
Acknowledgments M.N. El-Attug thanks the Faculty of Pharmacy, Tripoli University, Tripoli-Libya for the scholarship and financial support. K. Allegaert is supported by the Fund for Scientific Research, Flanders (Belgium) (F.W.O. Vlaanderen) by a Fundamental Clinical Investigatorship (1800209N).

\section{References}

1. Price KE, Chisholm DR, Misiek M, Leitner F, Tsai YH (1972) J Antibiot 25:709-731

2. Pien FD, Ho PWL (1981) Am J Hosp Pharm 38:981-989

3. White LO (1986) Trends Anal Chem 5:29-31

4. Weber A, Smith AL, Opheim KE (1985) J Clin Microbiol 21:419-424

5. Stevens P, Young LS, Hewitt WL (1976) Antibiotics 29:829-832

6. Ovalles JF, Brunetto MR, Gallignani M (2005) J Pharm Biomed Anal 39:294-298

7. Adams E, Hoogmartens J (2004) Curr Top Electrochem 10:63-70

8. Zawilla NH, Li B, Hoogmartens J, Adams E (2007) J Pharm Biomed Anal 43:168-173

9. Brajanoski G, Hoogmartens J, Allegaert K, Adams E (2008) J Chromatogr B 867:149-152

10. Yeh HH, Lin SJ, Ko JY, Chou CA, Chen SH (2005) Electrophoresis 26:947-953

11. Curiel H, Vanderaerden W, Velez H, Hoogmartens J, Van Schepdael A (2007) J Pharm Biomed Anal 44:49-56

12. Ackermans MT, Everaerts FM, Beekers JL (1992) J Chromatogr 606:229-235

13. Yu CZ, He Y, Fu G, Xie H, Gan W (2009) J Chromatogr B 877:333-338

14. Kaale E, Van Schepdael A, Roets E, Hoogmartens J (2001) J Chromatogr A 924:451-458

15. Anyakudo F, Kaale E, Govaerts C, Van Schepdael A, Hoogmartens J (2005) Trends Chromatogr 1:95-103

16. Wienen F, Holzgrabe U (2003) Electrophoresis 24:2948-2957

17. Flurer CL (1995) J Pharm Biomed Anal 13:809-816

18. Fang XM, Ye JN, Fang YZ (1996) Anal Chim Acta 329:49-55

19. Orsonneau JL, Massoubre C, Cabanes M, Lustenberger P (1992) Clin Chem 38:619-623

20. Martinek RO (1969) J Am Med Technol 31:678-696

21. Wood PL, Hill B, Hill PG (1987) Clin Chem 33:723-724

22. Rahmatullah M, Boyde TRC (1980) Clin Chim Acta 107:3-9

23. Ripamonti M, Mosca A, Rovida E (1984) Clin Chem 30:556-559

24. Berthelot MPE (1859) Chim Appl 1:284-293

25. Orsonneau JL, Meflah K, Connu G, Bernard S (1980) Ann Biol Clin 38:139-142

26. Naslund B, Stahle L, Lundin A, Anderstam B, Arner P, Bergstrom J (1998) Clin Chem 44:1964-1973

27. Krajewska B, Chudy M, Drozdek M, Brzozka Z (2003) Electroanalysis 15:460-466

28. Duffy P, Mealet C, Wallach JM (1988) Anal Chim Acta 211:205-211

29. Thavarungkul $P$, Asawatreratanakul $P$, Kanatharana $P$, Duenjumroon J, Chaibundit C (1999) Sci Asia 25:157-163

30. Schuchert-Shi A, Kuban P, Hauser PC (2007) Electrophoresis 28:4690-4696

31. Schuchert-Shi A, Hauser PC (2008) Anal Biochem 376:262-267

32. Been JV, Debeer A, Van Iwaarden JF (2010) Pediatr Res 67:83-89

33. Tayman C, El-Attug MN, Adams E, Van Schepdael A, Debeer A, Allegaert K, Smits A (2011) Antimicrob Agents Chemother 55:3990-3993 